\title{
Language of Instruction for Teaching Mathematics at Primary Level: Controversy in Pakistan
}

\author{
Saira Maqbool \\ Mamoona Ghani** \\ Saima Maqbool ${ }^{* * *}$
}

\begin{abstract}
One of the factors credited to the poor performance of students in Pakistan is the medium of instruction used at primary level. More than 70 languages are alive languages/spoken languages of Pakistan and its government is confused which language to select as MOI (medium of instruction) at primary level, i.e. Urdu which is the national language of Pakistan. This paper explores the MOI controversy in Pakistan it also sought to explore the possibilities and effectiveness of using English versus Urdu as a medium of instruction for the teaching of Mathematics in primary schools in Pakistan. A teaching experiment was conducted to compare the use of English as a medium of instruction with Urdu as medium of instruction in the teaching and learning of Mathematics to grade 3 class. $t$-test was applied to find of the difference of the progress between two groups, one group taught in Urdu as MOI and second in English as MOI. Major findings of the research indicated that the use of Urdu as a medium of instruction in the teaching of Mathematics to primary school students had a more positive impact upon the teaching of Mathematics. This discussion contains language controversy from the pre-partition time (1835-1947) till date in different political regimes to understand the causes of disagreement upon the selection of a single MOI in education. Applicable recommendations were made in the light of the findings.
\end{abstract}

Keywords: medium of instruction, language policy, controversy.

\footnotetext{
* Assistant Professor, Department of English, Allama Iqbal Open University Islamabad, Email: sana.sana98@yahoo.com

** Professor, Department of English, Islamia University of Bahawalpur, Pakistan, Email: Drghani2009@yahoo.com

${ }^{* * *}$ Assistant Professor, Khushal Khan Khattak University, Karak.

Email: Saima.maqbool@kkkuk
} 


\section{Introduction}

One of the fuming issues in many developing countries is the selection language of instruction to be used in the education system, although English is uniformly accepted as the international language of the world (De, 2002). The debate is to accept any vernacular or a lingua franca as the medium of instruction (Lavoie, 2008). Pakistan is a multilingual country. More than 70 languages are spoken in the different regions of Pakistan. There are six indigenous major languages, i.e. Punjabi, Sindhi, Pashto, Sariaki and Baluchi, and Urdu. Urdu is the national language as well is the official language, but the inherited colonial language is also the official language since its independence. Although a very small minority can understand this language still it exists as an official language due to multiple reasons, i.e. colonial legacy, need for administration and courts of law, wish of elites and others. This research strives to find out the effect of English and Urdu as medium of instruction in the subject of mathematics.

\section{Medium of Instruction and Academic Performances of Students}

According to Tehseen (2013) that medium of instruction applied in Pakistani schools is not understandable for learners. Their attention toward education creates a gap between student and teacher. This medium of instruction creates a barrier between education and environment. However, Pakistan has four provinces and every province has its own language and native uses different languages for communication inside the country, whereas the second language or official language of Pakistan is Urdu and English. Naveed et al., (2013) revealed that students have motivated and have positive attitude toward the use of English as medium of instruction. The findings of this case study indicated that, right learning strategies, supportive home environment, English medium background, and English communication skills played a vital role. These indications increase learner motivation, attention, attitude in their educational achievements and performance. Students feel more confidence and comfortable in educational environment.

Komba and Bosco (2015) described their findings as the learners who are from English background progress remarkably high as compared to the students who uses their first language or mother tongue for 
communication as well as learning. Their differences were found significant in statistical survey at $p<0.05$, in a two tailed test. Secondly, students who have English medium back-ground and there medium of instruction is also English at primary school level, students performed outstanding results in form of two national examinations than those natives who uses their first language or mother tongue. Results shown that English medium of instruction at primary school level have influenced significantly on the performance of student's abilities, perception, and understanding at secondary school level.

Rathore and Pancholi (2013) believed that students or learners could get command over second language or official language through proper communication and guide. Get the command over second language is very challenging or difficult for students and learners to be competent, we can say in other words that it increase learners confusion, complexity, fear, anxiety, and nervousness. Here the scholars and researchers have found that students and teachers of Gujarati medium college have full command about concepts and command in teaching. Teachers fulfill their all professional commitment, then English medium school teachers and students. Now, it's the great challenge for the teachers and school management how to overcome these issues.

\section{Vygotsky's Socio-Cultural Learning Theory}

The socio-cultural learning theory of Vygotsky is one of the most important theories in relation with cultural and language interference with learning. In this theory he states that learning is unmistakable in each individual student whereby the information and aptitudes obtained change starting with one individual then onto the next. It is indicated by Vygotsky that the principle point of instruction is to disguise culture and social connections through social learning. The significance of past encounters and information in translating present encounters is pushed. Studentse culture especially their home environment have a lot of commitment towards new information and aptitudes that one obtains. Language aptitudes are especially basic for making meaning and connecting new thoughts to past encounters and earlier information (Hamilton \& Ghalala, 1994): 255 in Dahms et al, (2007). It is contended that language assumes a dynamic part in the improvement of thought. Vygotsky claims that language assumed a basic part in subjective improvement this is because of the way that it is through language a learner figures out how to think and it is through words a learner disguises complex ideas. Along these lines, learning happens using 
language which an outer affair changes into inward process; for this situation discourse and language being the fundamental methods for correspondence that advances learning and learning prompts larger amounts of considering (Dahms et al, 2007). They likewise disclose that as indicated by Vygotsky two primary methods for learning are through social connection and language. Dialect empowers people to share encounters, in this way, improving the capacity to partake in social connection (Dahms et al, 2007).

\section{Teaching of Mathematics in Primary Schools}

Arithmetic is a science that deals with estimation, counts, finding relationships and managing issues. It includes basic reasoning, examining and critical thinking of space. It has a specific language in which symbols possess a most important place position (Sudhir \& Ratnalikar, 2003). Everyone regardless of class makes utilization of scientific learning somehow. Inability to use stabile teaching aids and techniques may result in rote learning only.

Mathematics is a bad dream for some students and has led to a science fever (Wu, 1995). One of Dube and Cleghorn's (1999) research discoveries is that students don't gain scientific grounds since they don't comprehend what they are instructed because of their incapability to get the language of instruction. The medium of instruction for mathematics in Pakistan is English (from third grade up t University). English is also the language for most science subjects, which is a remote language for general Pakistanis. This implies thae students battle with both the languae and Mathematical ideas. As indicated by Natsa(2006) the strength of English is something to be worried about.

According to Rose (2000) students can't grasp concept of the language he is taught in and his language of communication is not the same. The same point is highlighted by many researcher and promoters of mother tongue instruction who thinks that learners first language for mathematics can minimize 'instructional dead time'.

The living and learning style of an individual of a group is the effects of its culture. Similarly, Urdu culture also has impact on the learning of students and remember what they have learned in schools. It can be said that culture can have the capacity to form event their behaviors in learning mathematics. This scientific teaching method is denoted as 'ethno mathematics'. A Bazilian mathematician D'Ambrosio (1980s) was the first person who came up with this word. He explained it as 
unique cultural groups count, measure and identify with mathematical ideas (Nyota \& Chikodzi, 2010).

In 'Ethno mathematics' the instructor knows and learns about the living style of the learners' families and incorporate and mix them with their lessons. This involves the utilization of English as a language at primary level in the subjects of Mathematics and Science for the students. The basic concepts of counting, subtraction and addition of numbers can be merged in the Urdu by using Urdu language the students can understand and explain the amounts.

A research conducted on the effect of language in science and mathematics subject on learners' achievement resulted in understanding and teaching difficulties when the language used in classroom is not the language of society of spoken by the chilled outside the classroom. Studetns' may find two types of difficulties in articulation while being taught in forign language according to Bird and Wlford (1995). One is that learners will feel trouble in understanding of questions in an unfamiliar language and second students feel constraints of they are not able to articulate with clearity.

Mtetwe conducted a research on the subject of relationship of math and ethno mathematics in 1991. According to that it was found out that mathematics can be understood not only in English but in other languages in the same way. A universal field like mathematics can be learnt in different languages and it can mean the same thing.

In a research conducted by Nyagura's on grade seven students it was found out that the students who were taught in English and whose text books are in English cannot understand and mathematical ideas of simple day to day life about expansion, discount, interest, rebate and sale etc because these types of problems are mostly story based and needs reading and comprehending abilities on students part in English language which they eventually fail to solve.

Eisenchlas, Schalley and Guillemin while expressing the importance of mother tongue as medium of instruction, says that mother tongue has been preferred as medium of instruction in many developed countries (Eisenchlas, Schalley \& Guillemin, 2013). But situation in Pakistan is different. There are different proventioal languages spoken in Pakistan like Pshto, Balochi, Sindhi and Punjabi while our national language is Urdu. The other famous languages of Pakistan are Hindko, Brahui and Siraiki (Rhman, 1995). Since the separation of Pakistan form Subcontinent, the language controversy has been an issue or may be even before it according to (Nurullah \& Naik, 1943; Pachori, 1990). The ruling elites were divided into two parts on the subject of medium of 
instruction in the time of British rule. One was the Orientalists the supporters of vernaculars to be the medium of instruction while the other one was Anglicists the supporter of English to be the medium of instruction. Even today the issue of medium of instruction is unresolved. Khurshid expressing his concern, says that the issue of the medium of instruction in Pakistan has been raised in different institutions for different political issues many times. It was an issue an 1947 in the first convention on education and also in 2009 education policy.

\section{Research Methodology}

The purpose of the research was to examine the effectiveness of using English as medium of instruction in the teaching of Mathematics to primary school students, pre-test post-test equivalent group design was used. To the difference of achievement between the two groups taught to two different MOI.

\section{Population and Sample}

Population the study consisted of grade 3 students as they all are under influence of MOI. In this study a grade 3 class was sampled and used for practical teaching. From a large population of grade 3, the researcher selected a representative set of sample of level 3 students form English medium schools. Students having command over both the English and Urdu language was the need of the study therefor such schools were selected as sample.

Two schools were selected for the study through convenient sampling from the capital city Islamabad. The sampling method was selected because the participants are selected for data collection keeping in mind convince and availability for the study. Eighty students of class 3 were selected through random sampling method. 40 from each school, i.e. Al-Huda International School and Pak-Turk International School.

\section{Procedure of the Experimental Design}

For the current study Solomon four group design was selected as it divides the sample in to control and experimental groups for pre and post-tests to give the most accurate data about the groups progress and achievement. Four groups having 20 students in each group were made form the grade 3 classes in both the schools Group-A-I, Group A-II, 
Group B-I, and Group-B-II. Group A-I \& B-I learnt Mathematics using Urdu as the medium of instruction and Group A-II \& B-II were taught the same topics and concepts in English. All the variables including teacher, environment and lesson plan etc were tried to be kept the same beside the medium of instruction for all the four groups as per the requirement of experimental research.

The primary thrust for the research is provided by the practical teaching experiment, with four groups of 20 learners each of grade 3 as the subjects of the study. Kelly and Lesh (2000) argue that teaching experiments offer an opportunity to make direct observations about the learners' experiences, perceptions and reactions. Twelve lessons were designed to be taught three times a week for four weeks. Schools started at 8:30 am each day and ended at 2:30 pm. Each lesson was allocated 40 minutes. The concept of addition and subtraction of large numbers was the topic being taught throughout the experimental teaching sessions. The textbook as decided in the school curriculum, Countdown 4 by Oxford Publishers, was used for the experiment.

The initial phase of the experiment was to take pre-test form all the four groups. From the difference of the result the researcher could have found out if there exists any differences between the four groups which was the main goal of the pre-test in first place.

The pre-test consisted of 10 addition and subtraction type of question including such question as , add and subtract fractions with unlike denominators, add and subtract fraction with denominators of 10,100 and 1000, find the missing numerator/denominator in addition and subtraction sentence and add and subtract mixed numbers like and unlike denominators: word problems. Each right answer to the question was given 01 point (10 total points).The second step was to post-test each group after the treatment, i.e. teaching them Mathematics in English and Urdu as a medium of instruction. The post-test was also constructed following the pre-test pattern with advanced difficulty level. It was likewise scored in the same way as pre-test was. The score of Pre-test and post-test of the four groups were used to compare the performance of individual learners and the performance of the groups and the results were compiled and analyzed.

This design may best be represented as
$\mathrm{R} \mathrm{O} 1 \mathrm{X}_{1} \mathrm{O} 2$
$\mathrm{X}_{1}$ gain $=\mathrm{O} 2-\mathrm{O} 1$
$\mathrm{R} \mathrm{O} 3 \mathrm{X}_{2} \mathrm{O} 4$
$\mathrm{X}_{2}$ gain $=\mathrm{O} 4-\mathrm{O} 3$ 
Where:

$\mathrm{R}=\quad$ Random assignment of subjects to groups

$\mathrm{X}_{1}=\quad$ Exposure of a group to an Experimental (treatment) condition

$\mathrm{X}_{2}=\quad$ Exposure of a group to an Experimental (treatment) condition

$\mathrm{O} 1, \mathrm{O} 3=$ Pre-tests + Post-tests

$\mathrm{O} 2, \mathrm{O} 4=$ Pre-tests + Post-tests

Table 1

Comparison of Achievement Level of all the Groups in the Pre-test

\begin{tabular}{llllll}
\hline Group & Mean & Difference & $t$ & $d f$ & $p$ \\
\hline Group A-I + B-I & 25.50 & 0.9 & 0.917 & 36 & 0.528 \\
Group A-II + B-II & 26.40 & & & & \\
\hline
\end{tabular}

Table 1 show that independent sample T-test was applied to compare the mean score achievement level of the two sets of groups in the pretest. The test consisted of 10 questions having 50 marks. There is no significance difference between the achievement levels of the two sets of groups in the pre-test. All the groups showed average performance in the pre-test the level of significance is 0.528 .

Table 2

Comparison of the Achievement of Both Sets of Groups in the Post-test

\begin{tabular}{llllll}
\hline Group & Mean & Difference & $t$ & $d f$ & $p$ \\
\hline Group A-I + B-I & 38.43 & 8.48 & 2.42 & 38 & 0.02 \\
Group A-II + B-II & 29.95 & & & & \\
\hline
\end{tabular}

Table 2 reveals that Group A-I + B-I performed better and scored better having 38.43 mean score, than Group A-II + B-II having 29.95 mean score. Though the difference between the performances of both the groups is significant and the progress is visible.

Table 3

Comparison of Mean Scores of all the Groups

\begin{tabular}{llllll}
\hline Group & Mean & Difference & $t$ & $d f$ & $p$ \\
\hline A-I + B-I & 12.93 & 9.38 & 2.97 & 36 & 0.013 \\
A-II + B-II & 3.55 & & & & \\
\hline
\end{tabular}

Table 3 shows a further comparison of the mean scores of the two sets of groups. It shows as well that the achievement of Group A-I + B-I 
(Urdu as Medium of instruction) is more than Group A-II + B-II (English as Medium of instruction). The significance level is 0.013 that is less than .005 .

\section{Conclusion}

English was introduced in the education by the Britishers (18571947). English was made the way to join the civil services. The purpose behind this step was to create a class of people who would share the same interests as the rulers. Even after the Britishers left, they left this legacy behind and this system continued even after independence in 1947. The elite class made this possible. English medium schools were established for the rich and Urdu medium for the poor masses.

After independence Urdu was considered to be the unifying power of the nation. The nationalists have a strong desire to unify the nation by one language. But instead of promoting the national unity, it became a source of disintegration and the declaration of Urdu as the national language made East Pakistan to become independent in 1971. Thus the Urdu Bangali controversy came to an end. However, the making of Bangladesh as an independent state in 1971 resolved the Urdu-Bengali controversy. But the problem was still not resolved. In the constitution of 1973 Urdu was selected as the official language and it was decided that it would replace English within fifteen years. English would only act as de facto official language until then. it was decided that the reason behind this controversy was the dilemma of this situation. It has been around for forty three years instead of fifteen since that constitution, even still the situation is the same. The nation is still divided between the two, i.e. the elite and the poor and so is our education system and English is still the power of the elite. This is the reason that we have yet not been able to implement an effective system of education. The Education Policy of 2009 has declared the promotion of English in the government schools. The purpose behind this decision is to include the masses in the mainstream of development.

The teaching experiment proved that the students taught through the medium of Urdu, i.e. Groups A-I and B-I showed more progress than the groups who were taught through English. The mean score of the pre-test of Groups A-I and B-I was recorded as 25.50, while the score in the posttest became 38.43. The mean score of the pre-test of Group A-II and BII was recorded as 26.40, while the score in the post-test became 29.95. Thus the differences between the mean scores of the pre-tests and posttests are 12.93 and 3.55 for Group A-I+B-I and Group A-II+B-II 
respectively which proves that the students taught through Urdu has progressed more than those taught through English.

\section{Findings of the Study}

Through the comparison of pre-test of achievements of all the groups it as clear that there is no significance difference between the achievement levels of the two sets of groups in the pre-test. As both the groups mean score are almost the same whereas the score of the comparison of the achievement of both the groups in post-test are significantly different the progress of group. The finding of the last table further clarifies the fact that the progress Urdu as medium of instruction is greater by the comparison of mean scores of all the groups.

\section{Recommendations}

As the finding of the study suggests that pre-test score of both the groups are the but in post-test the progress of Urdu as MOI has significantly greater. Keeping in view the result government of Pakistan should adopte a positive role in making a language policy wherein Urdu would be deemed to be as important, if not more, as English. The Education Act of 2008 could be revised. Entry tests into universities tertiary education should assess the language abilities in Urdu along with English of aspiring scholars. Thus national GRE should have an Urdu portion along with English

This research adds significant knowledge in the body of existing researches on factors effecting student's achievements at grade 3 as it helps in identifying the fact that Urdu as MOI can produce better results than English at young level.

Further research may be undertaken to verify the findings of existing studies into the efficacy of using Urdu languages to impart education right from the primary level.

The Government keeping view the analysis of this research may formulate a body of Urdu experts who could translate in Urdu the materials available on science, technology and mathematics so that the transition from English could be smoother.

As the research proves that Urdu is better as medium of instruction in the light of such result the policy makers should form a committee which should coin or create such scientific terms that have no equivalent in Urdu to dispel the misgivings of the stakeholders with regards to the 
inadequacy of Urdu to be employed for didactic purposes, specifically in the areas of mathematics, science and technology

Through the finding of the study we also came to know that there exists different educations systems that uses different MOI in classrooms. The government of Pakistan should ensure a uniform system of education throughout the country, having Urdu as medium of instruction this would banish the fear of government school students of remaining disadvantaged and all the primary school students will progress equally. 


\section{References}

Abdullah, S. (1976). Pakistan mein Urdu ka masla. Lahore: MaktabaKhayaban-e-Adab

Basu, A. N. (1947). Education in Modern India: A Brief Review. India: Orient Book Company.

Brown, M. E., \& Ganguly, S. (Eds.). (2003). Fighting words: Language policy and ethnic relations in Asia. Cambridge: Mit Press.

Cooper, R. L. (1989). Language planning and social change. UK: Cambridge: University Press

De Klerk, V. (2002). Language issues in our schools: Whose voice counts? Part 1: The parents speak: Many languages in education: Issues of implementation. Perspectives in education, 20(1), 1-14.

Dube, R., \& Cleghorn, A. (1999). Code switching in mathematics lessons in Zimbabwe, Zimbabwe Journal of Educational Research (ZJER), $1(1), 1-13$

Eisenchlas, S. A., Schalley, A. C., \& Guillemin, D. (2013). The importance of literacy in the home language: The view from Australia. Sage Open, 3(4), doi:2158244013507270.

Government of Pakistan (GoP). (1966). Report of the commission on student problems and welfare (RCSP): Summary of the important observations and recommendations. Karachi: Ministry of Education.

Jaji, G., \&Nyagura, L. M. (1989). Attained mathematics curriculum in Zimbabwe primary schools. Zimbabwe Journal of Educational Research, 1(2), 147-167.

Kaplan, R. B., \& Baldauf, R. B. (1997). Language planning from practice to theory, Multilanual Matters. 15(1), 106

Khurshid, A. (1987). Hamara Nizam-e-Taleem. Intitute of Policy Studies. Pakistan: Islamabad.

LAD-F: Legislative Assembly Debates of the North-West Frontier Province. 
Lavoie, C. (2008). Hey, Teacher, Speak Black Please': The educational effectiveness of Bilingual Education in Burkina Faso. International Journal of Bilingual Education and Bilingualism, 11(6), 661-677.

Naik, J. P., \& Nurullah, S. (1974). Students' history of education in India 1800-1973. India: MacMillan company of India limited.

Pachori, S. S. (1990). The language policy of the East India Company and the Asiatic Society of Bengal. Language Problems and Language Planning, 14(2), 104-118

Rahman, T. (2010). The education system in Pakistan with respect to inequality. Shaping a nation: An examination of education in Pakistan, 231-261. Karachi: Oxford University Press.

Rahman, T. (2010). Urdu as the language of employment in court and office in British India. Pakistan Perspectives, 15(2), 11.

Rahman, T. (2006). Language policy, multilingualism and language vitality in Pakistan. Trends in linguistics studies and monographs, 175, 73. Berlin and New York: Mouton de Gruyter.

Rahman, T. (2005). Passports to privilege: The English-medium schools in Pakistan. Peace and Democracy in South Asia, 1(1).

Rahman, T. (2003). Impediments in the development of S \& T: Cultural and Social Structure. Towards Understanding the State of Science in Pakistan, 78-85. Karachi: Muizz Process.

Rahman, T. (1998). Language, religion and identity in Pakistan: Language-teaching in Pakistan madrassas. International Centre for Ethnic Studies, 16(2).

Rahman, T. (1996). The history of the Urdu-English controversy in Pakistan. Modern Asian Studies, 31(1), 177-201.

Rahman, T. (1995). The Pashto language and identity formation in Pakistan. Contemporary South Asia, 4(2), 151-170.

Richey, J. A. (1922). Selections from educational records part II 18401859.

Rose, M. (2000). 8 ways to better teaching. The Education Digest, 65(6), 52. 
Wu, W. T. (1995). Effects of Kumon Instruction on Children's Math Achievement, Attitudes, and Anxiety. Gifted and Talented International, 10(2), 76-84.

Zulfiqar, G. H., \& Akhtar, N. (1986). Qaumi Zaban Ke Bare Men Ahem Dastavezat.

\section{Citation of this Article:}

Maqbool, S., \& Ghani, M., Maqbool, S. (2018). Language of instruction for teaching Mathematics at primary level: Controversy in Pakistan.

Pakistan Journal of Education, 35(1), 83-96.

Received on: December 06, 2016

Revised on: February 21, 2018

Accepted on: March 28, 2018 